\title{
Generic Challenges AND Automation SOLUTIONS IN MANUFACTURING SMES
}

\author{
David Grube, Ali A. Malik \& Arne Bilberg
}
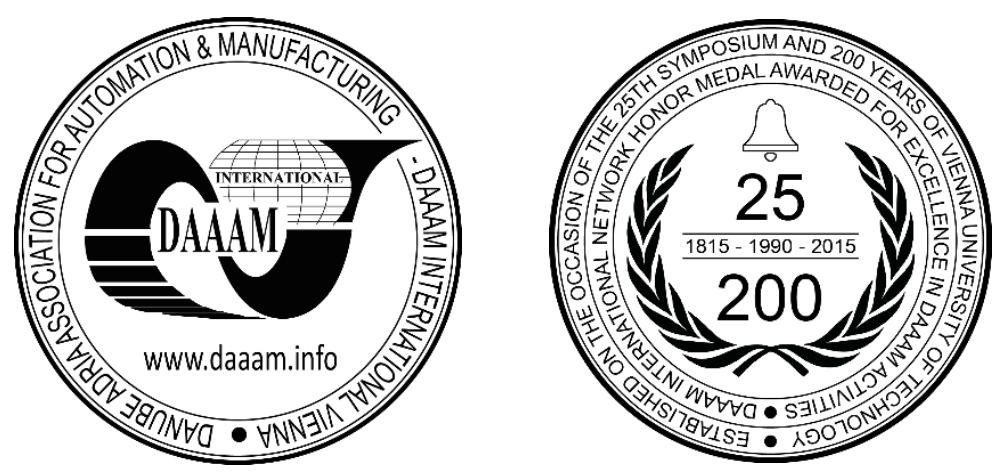

This Publication has to be referred as: Grube Hansen, D[avid]; Malik, A[li] A[hmad] \& Bilberg, A[rne] (2017). Generic Challenges and Automation Solutions in Manufacturing SMEs, Proceedings of the 28th DAAAM International Symposium, pp.1161-1169, B. Katalinic (Ed.), Published by DAAAM International, ISBN 978-3-902734-11-2, ISSN 1726-9679, Vienna, Austria

DOI: $10.2507 / 28$ th.daaam.proceedings.161

\begin{abstract}
Evermore research is conducted on smart manufacturing, digital manufacturing and other aspects of what is expected from the fourth industrial revolution known as Industry 4.0. Most of the research of Industry 4.0 is currently a better fit for large corporations than for SMEs, which in Europe however represent $98 \%$ of the manufacturing industry. In general, SMEs produce high-mix low-volume products, which require a high degree of flexibility. Historically flexibility and automation have been contradictory, but as automation becomes smarter, digitalized and less expensive, this may change which this paper is going to challenge in the context of Lean automation. Through a two-year automation research project where several automation solutions were built and implemented, it was verified that SMEs face very different challenges. In this paper the analysis of the companies, and automation integrators of the project, identifies a correlation between the challenges, age and size of the companies. The identified correlation lay ground for an Industry 4.0 light concept, targeting the identified generic challenges of companies employing 10-50 people. The solutions presented are based on cloud computing, Internet of Things and horizontal integration to simulate digitalized order handling and traceability in smaller companies.
\end{abstract}

Keywords: SME; Lean Automation; Industry 4.0 light; HMLV manufacturing; IoT

\section{Introduction}

SMEs generally operate in the paradigm of high mix low volume (HMLV) production and often act as a specialized supplier to larger companies. SMEs are characterized with production systems that are less automated and rely more on human aspect of production and hence exhibit higher flexibility. Consequently, they are in better position to adapt quickly to customers' demands and offer customized products, the challenge however is their productivity and level of automation especially in high salary countries in Europe. Globalization, market changes and not least digitalization technologies challenge manufacturing businesses to think in smart innovative solutions [1] [2]. A range of manufacturing development initiatives are available in industrialized economies such as Industrie 4.0 in Germany, Advanced Manufacturing Partnership in the United States and Manufacturing Innovation 3.0 in the Republic of Korea [3]. These initiatives are harvesting solutions for manufacturing companies around digitalization and internet connectivity. 
The new production landscape is envisioned as getting full benefits of cyber physical system (CPS), Internet of Things (IoT) and digital twins. It is evident from the research and industrial innovation projects that these technologies are being cultivated around large multinational companies and there is not much research available for the development of SMEs in context of digitalization and smart manufacturing. Now scholars, politicians and industrial leaders are talking about a fourth industrial revolution (I4.0) that will elevate the productivity of manufacturing to unpreceded levels. The transition will utilize state of the art technologies within automation and digitalization of both products and entire value chains [4]. Industry 4.0 is gaining momentum and is widely known by both SMEs and larger corporation, as an example, $85 \%$ of the companies in Denmark are aware of I4.0 and are paying attention to it [5]. Despite the considerable attention, the share of research and development into Industry 4.0 for SMEs, compared to larger enterprises, is limited. This makes it hard for the smaller companies to grasp the knowledge, which however is important because SMEs are also in the middle of the fourth industrial revolution. SMEs may in the near future face technologies and solutions that they have to be aware of, to be able to take advantages of new functionalities and services in relationship to existing products and businesses. If not aware of these new opportunities in digitalization and automation, this may in worst case disrupt their businesses. It is well known that production systems and control hierarchy of SMEs are considerably different when comparing with larger enterprises [6] and recent studies conclude that company size is closely related to preparedness towards Industry 4.0, automation and digitalization [7].

Research Question: How can we make use of digitalization and Industry 4.0 enablers to develop generic solutions that can remedy challenges in several SMEs?

The scientific contribution of this paper is to:

- Investigate the challenges for flexible automation in SMEs in industrialized countries

- Propose flexible automation solution(s) to increase productivity of manufacturing SMEs

- Present the technical solution with the help of a learning-factory model

\section{Literature review}

The literature review is describing both what has been identified as challenges to manufacturing SMEs and how I4.0 is expected to impact manufacturing SMEs. In the literature complimented with case studies, it becomes clear that there are many variables that determines the challenges SMEs are facing, and also that the challenges may be different according to company size, history, business area, geographical location etc. This form of difference is also visible when SME related challenges are evaluated, and often the studies are formed in a local context [8].

\subsection{SMEs for sustainable society}

The annual report of European SMEs [9] exhibits the data on the role of SMEs in Europe. It states that SMEs have a share of $99.8 \%$ of total enterprises in Europe, are employing $66.9 \%$ of all enterprise' employees and add $57.8 \%$ value of all enterprises. In the past decades, much of the productivity gain is enabled by lean and similar productivity enhancing philosophies. Thus, the lean philosophy did not only gain attention in business-companies, but also in academia where the challenges, benefits and prospects of lean manufacturing were described. Considering the published research, the papers count for lean manufacturing is more than 70.000 articles and the share for SMEs related lean-manufacturing is almost 17.000 papers. But despite the great attention from both industry and academia, most of the SMEs remained struggling to implement lean methods in their production systems. Some of the main challenges in implementing lean were the lack of time and resources. Another challenge being faced by SMEs was the uniqueness of SMEs in their nature thus it was hard to form generalized lean tools to fit the company needs [6]. This gives rise to the hypothesis that SMEs will again face even bigger challenges in implementing automation and digitalization, considering the fact that the solutions are still not tailored to their needs and the fact that automation historically has remained away from SMEs.

\subsection{The next industrial revolution}

It is a human characteristic to struggle for improvements in their environment and quality of life. Factories, as a strong component of economic wellbeing of the society, have progressed rapidly in-line with these improvement related expectations. This is evident from the fact that humans have already experienced three big transformation or revolutions within industrial paradigms [10]. There have always been some technological enablers that gave rise to this notion of industrial revolutions i.e. steam engine, electricity, and PLCs for the $1^{\text {st }}, 2^{\text {nd }}$, and $3^{\text {rd }}$ industrial revolutions respectively. Now the recent developments in the field of information and communication technologies (ICT) foretell us to enter into a new industrial paradigm named Industry 4.0 (I4.0) or the fourth industrial revolution. The emergence of the term of Industry 4.0 happened in the last decade in Germany as a strategic initiative of the German government as part of the "High-Tech Strategy 2020 Action Plan" in 2011, describing it as the increasing ICT integration in production and manufacturing [11]. Industry 4.0 now refers to a network approach where components and machines ("things") are becoming intelligent and act as modular bricks (like LEGO bricks) to setup larger systems [12]. 


\subsection{SMEs in era of lean automation and digitalized manufacturing}

There has been a varied view towards the impact of Industry 4.0 on SMEs. The initial reports on Industry 4.0 stated that Industry 4.0 will benefit manufacturing SMEs to a great extent [4] whereas many other articles dealing with Industry 4.0 state that SMEs will become victims of this new digitalized manufacturing landscape [7]. In the relatively new literature stream of Industry 4.0 it has become evident that SMEs are under-represented in research field i.e. only $6,5 \%$ of the literature related flexible automation target SMEs, despite the fact that SMEs hold for $98 \%$ of the companies in the European Union.

According to Kolberg [12] Industry 4.0 phenomena has a close match with Lean philosophy meaning that increased integration of ICT will improve Lean production thus translating Industry 4.0 from science to reality. Some scholars state that Lean and automation contradict each other [13] and therefore earlier industrial automation did not try to couple Lean and automation. But in our research and experience in SME's, it is observed that Lean and automation can be closely related and ought to be combined in manufacturing strategies. Flexibility, as stated earlier is one of the crucial elements in manufacturing. There are many definitions of flexibility, but in the research context, it is about the ability to respond to changing demands from customers, which is different in SME's. Often automation is understood as robotics, but this is not the only and often not the most important solution, when talking SME's flexibility.

Lean Automation means in this context that automation has to focus at the customer, it has to create value and eliminate waste. The Toyota Production System operates with the expression Jidoka, known as "automation with a human touch". This is very much what Lean Automation is about, to use robust, reliable components build into non-complicated, not over engineered solutions. A challenge for Lean Automation is to determine the appropriate level and type of automation, where Bilberg and Hadar [14] presented lean semi-automated cells, where the automation is within the manufacturing process, while the planning, the material flow and part of the inspection is handled through the flexibility of the workers. According to Seifermann [15] traditional automation especially in western countries often become complex and expensive, and therefore the conclusion, especially when addressing SME's, is that low cost Lean Automation solutions may be the right concept.

According to Jackson [13] the challenges in Lean Automation are:

- The ability to choose the right level of automation as well as the right automation solution

- The ability to develop automation solutions which are flexible and reconfigurable, that enables the system being changed and adapted to new demands during its lifecycle

- The ability to handle complex equipment without being an expert. The requirements are intended to reduce the perceived level of complexity, possibly through intuitive user interfaces

- The ability to change and implement changes in a given automation system due to changes in the products

Besides challenges, as discussed above, Mrugalska [16] has described the strengths of SMEs towards innovation. These strengths distinguish them from large companies and may even place them in a stronger position for digital transformation.

The strengths are:

- $\quad$ Fast decision making

- Fewer layers of management

- Simple and direct communication

- SMEs are close to customers and get faster feedback and response quickly to customer's needs

- Higher flexibility at all levels

- Easy to introduce change and new methods

Jaione [17] has developed a three-stage model for SMEs to mature and become capable of developing the preconditions for an Industry 4.0 setup, they are well aware of some of the challenges regarding the concept of Industry 4.0, but at the same time, they believe that their three-step model can ease the road towards Industry 4.0. First step is to envision Industry 4.0 into a vision, second is to enable Industry 4.0 by means of a roadmap and third step is to enact Industry 4.0 by running simple bottom-up project towards Industry 4.0.

\section{Empirical case study - the AutoSyd Project}

In order to investigate the potential for SMEs based on automation and smart technologies, a research project was conducted targeting SMEs in the region of Southern Denmark. The aim was proliferation of knowledge and innovationbased-automation into the SMEs. For this, an action research approach was adopted to engage with industries, investigate the problems, create knowledge and contribute to scientific literature in a broader sense [18]. The project has been in contact with more than 100 SMEs in the southern part of Denmark. Forty of these SMEs were analyzed in-detail for mapping the current state and to point at future automation potentials. 
The research carried out an extensive study to analyze the needs and thus develop automation solutions for 14 manufacturing companies. Consequently, 10 SMEs were selected to test the development plan. The solutions were developed following an iterative process with partner companies to develop possible frameworks for automation to address their manufacturing challenges.

The researchers designed a framework for how to get an insight of the company. The procedure adopted consisted of an introduction by the owner/director of the company, discussion on how they operated, what was important to them, and who their customers were. The introduction-session ended with an extensive and informative guided tour through the production facility where all significant processes were described, measured and captured in an internally developed scheme. The scheme was developed based on well-known operations management tools presented e.g. by Heizer and Render [18] and Lean literature [19]. Later, recommendations on what and how to automate was handed over to the company accompanied by a roadmap to proceed in the iterative process.

Observations from a two-year automation research project point towards the fact that SMEs in the span of 1 to 205 employees have indeed very different challenges, but also generic challenges were observed, and many of the SMEs seem to be equally ready to implement technology and automation to overcome challenges. Hence the question, how can SMEs be targeted with generic digitalized automation?

\section{Findings in SMEs}

\subsection{Challenges with respect to evolution of an SME}

Based on our observations, SME experiences different types of challenges at different phases of its maturity, where the number of employees has also close impact on this trend. In the figure (Fig. 1.) a summary of challenges is presented in relation to the number of employees as an indicator for the progressive evolution. For this work, SMEs are defined according to EU standard i.e. below 250 employees and up to $€ 50$ million in turnover. In the AutoSyd project companies from one employee to 201 employees were observed, plus we have information from bigger companies i.e. above 250 employees. In brief, it is often observed that for micro companies the challenges are the products, markets and the financing. The smaller companies observe challenges in procedures, documentation and productivity. The medium sized get challenges with the size of organisation, communication and considerations according to automation. This paper research the opportunities for SMEs to start automation even earlier i.e. for small SMEs.

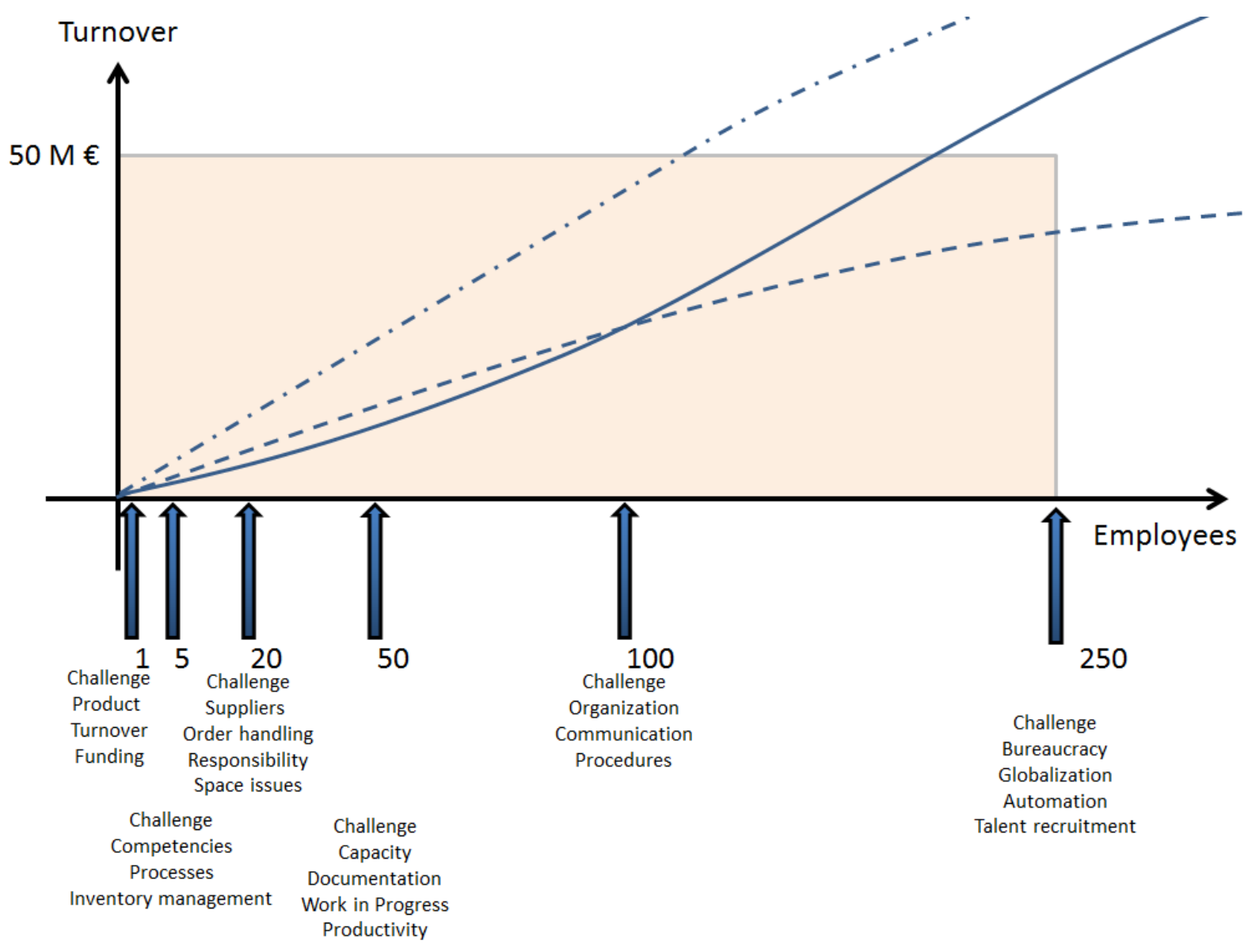

Fig. 1. Generic challenges of SMEs as identified from the AutoSyd research project 


\subsection{Generic challenges for SMEs - findings from the research project}

Investigating the mentioned SMEs, general issues recur. SMEs are often within niche and specialized production, based on key technologies, which often results in High-Mix Low-Volume (HMLV) production. Most SMEs in this research did not have a clear strategy for their production and investments. Machines and equipment are fitted in the production, where space is available, without long term planning.

The inventories and flow of materials was unnecessary complex, with high work in progress -WIP, long lead times and many "dead" components in production. The planning and operations were often done manually without proper tools and procedures, which makes it hard to prioritize and keep the overview. Generally, there were high variety in volume (high/low volume), product/services and lead times. Quality, flexibility and adaptability has high attention in the SME's, but is challenged by many manual processes, complexity in structures and lack of overview.

The identified challenges are summarized to:

- Most SME's in this research did not have a strategy for their production and investments

- Machines and equipment is fitted in the production, where space is available, without long term planning

- The inventories and flow of materials was unnecessary complex, with high work in progress -WIP

- Long lead times and many "dead" components in production

- The planning and operations are often manual.

- High variety in volume (high/low volume) and mix of product/services

- Quality, flexibility and adaptability has high attention in the SME's, but is challenged by many manual processes

- Complexity in structures and lack of overview

Based on the experience throughout the project and findings above, the overall conclusion is that:

- SME's must work strategically with production that makes more long-term planning possible and consistent.

- The planning and control systems must be simple and efficient solutions to support personal at the shop floor, to make right decisions.

- Focus at Lean tools to reduce waste and create flow, to prepare for automation.

- SME's must think smart in simple Lean Automation solutions, that may be specific to the individual companies, but still there are some general learnings and benchmarking between companies.

\section{Generic solutions for SMEs}

The research and collaboration in the consortium between the university and the automation providers, has resulted in three generic concepts for automation solutions to SME's in line with the approach of simple Lean Automation. The solutions applied in this project, are all modular and can be multiplied to larger scale and adapted to new situations. The simple Lean Automation solutions are flexible and can be reconfigured.

\subsection{The Production Feeder}

Most SMEs have CNC machines (milling, turning etc.) with manual material handling. In this concept, a flexible feeder system has been developed to feed CNC machines automatically. The innovative element in this solution lies in the feeder, that is flexible and adaptable to any type of robot and flexible to new products. The feeder has a flexible magazine that by a human can be filled/emptied with products (while CNC-robot is working), the robot and CNC machine can then work for several hours without interference of a human.

The feeder is based on flexible modules, i.e. it can be rebuilt and reconfigured to new tasks. The feeder is mounted at wheels, so that it can move between machines. In this way, the CNC machine can also be operated manually if required. This concept increases flexibility and Overall Equipment Efficiency -OEE.

\subsection{The Flexible Assembly cell}

Most manufacturing SMEs have assembly tasks and demand more flexible assembly, that are easy to change and setup for new products. This concept is built of flexible modules that through different configurations can be operated by the operators themselves. The concept can be configured for different levels of automation, where assembly and handling may be by any combination of humans and/or robots in collaboration.

The robots will in the final setup be moveable and operate as helping devices for simpler work tasks, where the humans handle the more flexible and complicated tasks. The assembly cell concept provides a high degree of flexibility and scalability, combining the best characteristic from both automation and human operators. 


\subsection{Module based Pick and Place cube}

This Pick and Place cube or cell, is designed to only take up the space of a regular production worker, it is highly modular, meaning that the capacity can be scaled up and down by simply adding more cubes. The hard wiring is simple, one power connection and one pneumatic connection and the system is up and running. The data is cloud based, and can be seamlessly up and downloaded, the data will then be presented on a standard of the shelf screen. On the same screen the Human Machine Interface (HMI) is made intuitive, for example the function for programming consists of dragging and dropping elements. It is possible continuously to get access to the helpdesk programmers for keeping the uptime at a high level. The cube itself has been designed for portability by means of a simple low lifter, this means that an SME with more production lines can move the cube very easily between lines and then plug in the connections.

The three examples of products/concepts described above are solutions/products coming out of the research and collaboration, where most likely none of these solutions would have been developed without the complementary competences between university and industrial system providers. There were also three other solutions that most likely will be turned into products in the near future. One of them is a simple planning system based on cloud technology and internet communication on the direction of internet of things.

\section{Technologies for future research in SME context}

The smart manufacturing paradigm is highlighting various technological enablers to transform manufacturing landscape. As already discussed, it is significantly hard for SMEs to research and develop the architecture for those technologies on their own. However, we are highlighting below technological enablers, that are part of the Industry 4.0 paradigm and carry a benefit potential for SMEs.

The technologies identified are in accordance with the challenges investigated in SMEs, development effort and maturity level of the technologies. The future research by the authors will investigate further into these technologies in cooperation with regional SMEs. In this regard an Innovation-Lab is setup at the Mads Clausen Institute of University of Southern Denmark. The Innovation-Lab is a state-of-the-art facility that offers collaboration opportunities between academic researchers and industrial partners to develop innovative solutions for manufacturing and production enterprises.

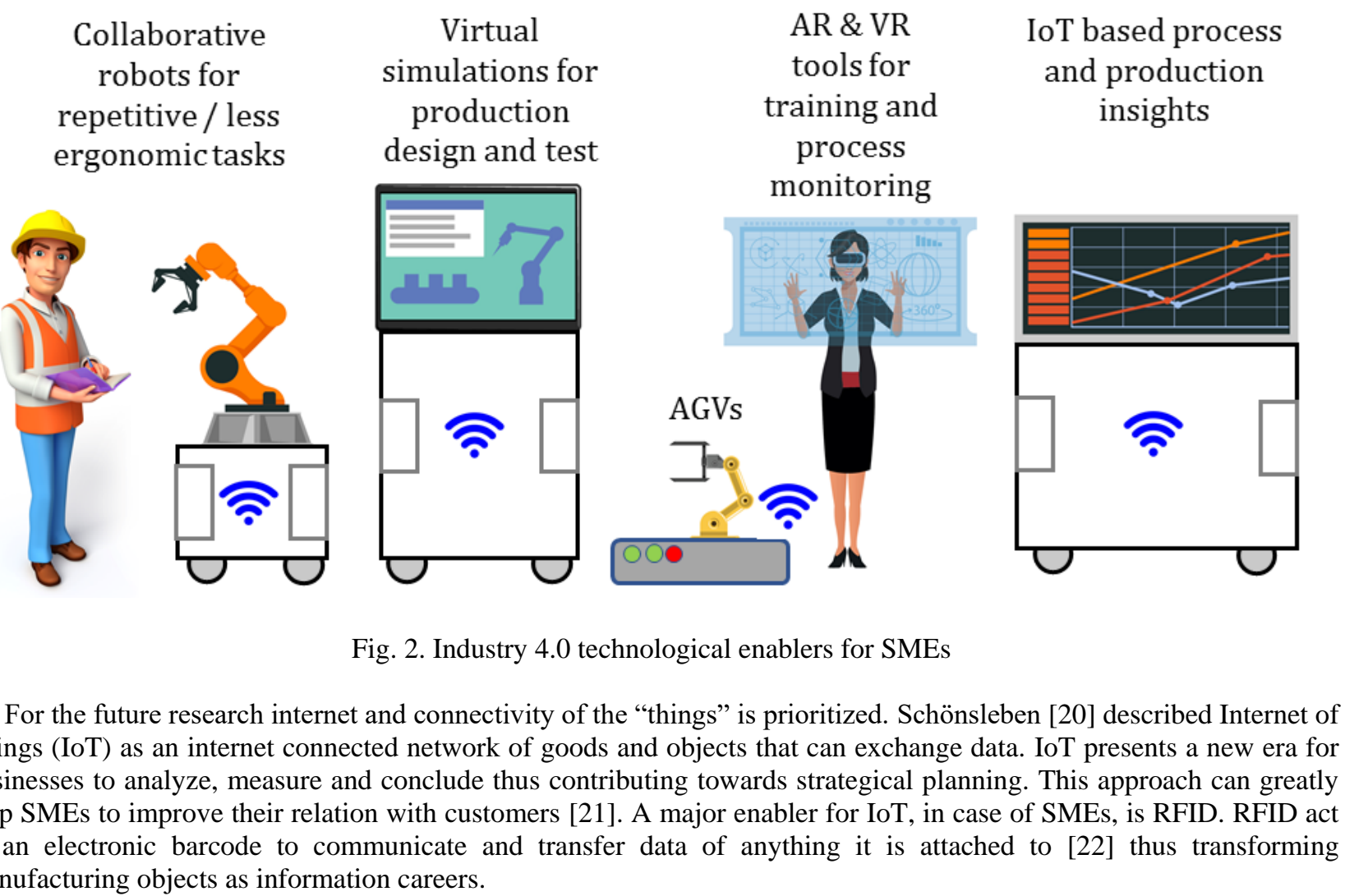
manufacturing objects as information careers. 
Many advantages of RFID tags can be conceived in SMEs in material movement, resource planning and logistics. The data that is collected with the network of "things" is high in volume and because of its evaluation complexity, it is referred to as Big Data. The aim of doing so is to improve decision making process and reduce risks [20]. The investment to use this technology is huge however Cloud technology and Hadoop systems can be an effective solution both in terms of investment and number of employees required to manage and analyze the data.

At the site level of a production system, a big opportunity can be investigated in the movement of the material. Conventionally automated guided vehicles (AGVs) are used to be guided by cables mounted in the floor, and only big companies have had access to this type of internal transport. However now much more flexible solutions are becoming available, which are simple less expensive moveable robots and are easy programmable. So, the target customer also may be SMEs. We will see collaborative AGVs like the robots in near future. Another emerging trend in production automation is towards collaborative robots or cobots. In a collaborative environment, the production tasks can be distributed based on strengths of robots and humans.

The distinguishing features of collaborative robots are their safe and effective interaction with human workers and ease of deployment and operation. Productivity, ergonomics, and safety conditions are potential areas of getting benefit from collaborative robots [23][24]. Although SMEs are characterized with low volume of production with high mix and hence robotic automation has remained far from SMEs, but with the concept of lean automation the repetitive and less ergonomic tasks at the shop floor can well be assigned to collaborative robots.

The design and optimization of new as well as existing production system around these technologies will be a challenge, and in this regard, manufacturing simulations are an effective way to support the decision-making process. Creating a virtual model of a system that imitates the characteristics of the physical model is far cheaper to experiment before implementing in the real world. The modern simulation tools are getting much stronger in simulating complex scenarios with easier to use interfaces.

\section{Smart Factory - the scaled model}

A scaled production facility has been built-up to showcase and demonstrate the application of simple, easy to use smart technologies in SMEs. The inspiration to this scaled learning factory is SmartFactory [25] setup built up at DFKI, Germany, which is a hybrid production facility as a demonstration and development platform of Industry 4.0 related technologies[26]. The machinery and components used in the SmartFactory are similar to those used in industrial application and offer the same complexity as an industrial equipment [27].

A similar concept is used to build up learning factories in other research institutes e.g. Process Learning Factory at the Institute of Production Management, Technology and Machine Tools (TU Darmstadt), The IFA Production Training for teaching lean production methods at the Institute of Production Systems and Logistics (Leibniz University Hanover) and Experimental and Digital Factory (EDF) at the Department of Factory Planning and Factory Management (Chemnitz University of Technology) [28]. Wagner [28] is of the views that these experimental environments are an effective way to develop and demonstrate innovative concepts and educate industry practitioners as well as students about their potential.

In the AutoSyd project, contrary to learning factories in practice, a scaled model approach is adopted. The purpose is to build a low-cost factory setup with easy to use wireless "plug and produce" components to demonstrate innovative technologies to SMEs representatives. This model can be easily setup and rebuilt when required. The developed showcase is based on cheap and simple digitalization components such as RFID tags, embedded microcontrollers, Rasberry Pie LEGO bricks AND Little Bits, combined in a simple but illustrative setup that monitors and delivers the exact machine hours, man hours, material usage and process traceability. The scale model has caught great attention, because of the simplicity, it can be operated stand-alone or integrated to existing systems, and the model solely provides the information for handling orders, monitor and control operations until creating the invoices.

The learnings from working with the scale model with SMEs is that, instead of trying to explain the entire philosophy behind Industry 4.0 and the technologies, a simple setup that utilizes digitalization technologies, in this case, RFID, embedded microcontrollers and cloud solutions, elevated the willingness towards embracing the technologies which the politicians, industry leaders and consultancy companies appraises. In other words, a simple bottom-up solution to demonstrate part of Industry 4.0, where other of the enabling technologies described above are expected to be demonstrated in a similar setup. 

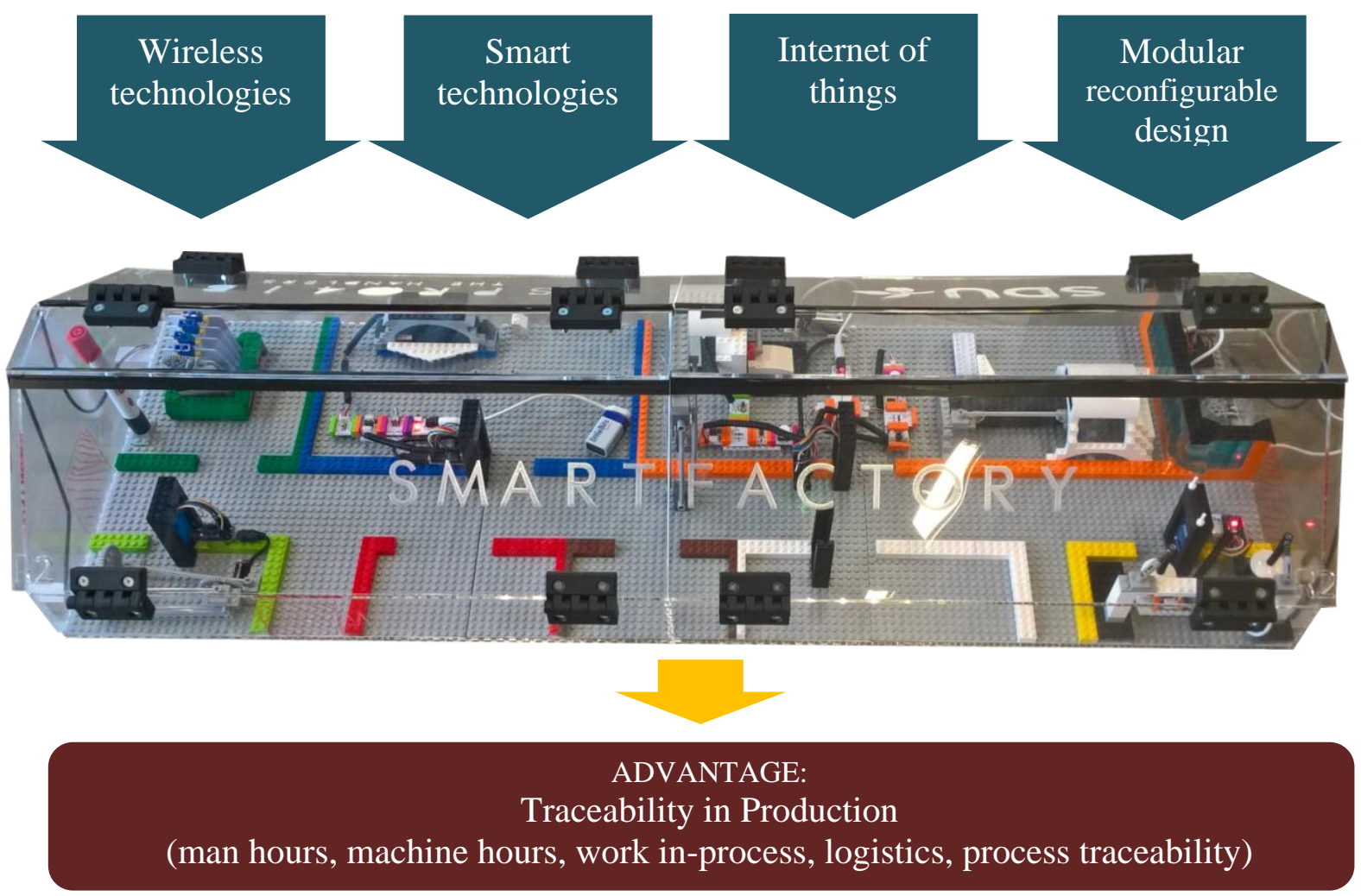

Fig. 3. A 1:50 scaled Smart Factory

\section{Conclusion}

Despite the fact that SMEs play a major role in production businesses of Europe, only limited research exists on how to increase productivity and automate SMEs. This is causing the SMEs to fall behind their contemporary large sized enterprises on the way to digitalization and smart automation. Based on literature and practical cases this paper is pointing at generic challenges and solutions to SMEs focusing at HMLV production, however the challenges and solutions are different depending on the evolution stage of an SME. Lean and automation are investigated as ingredients in automation solutions for SMEs, where automation with a human touch or "autonomation" is in focus. It is presented that strategic focus at production with "simple" smart technology concepts can enable SMEs to become more adaptable to the changing and dynamic environment e.g. collaborative robots and AGVs in a reconfigurable environment can adapt to changing environment. The future approach will be to investigate further into Industry 4.0 enablers and for Industry 4.0 -light approaches that foster Smart Lean automation solutions to SMEs. The research will further aim to ensure competitiveness by creating sustainable digitalization and automation solutions that are easy to use, cost competitive and flexible to HMLV production.

\section{References}

[1] Shah, R.; Park, H. \& Lee, G. B. (2016). Design for assembly: an approach to increase design efficiency of electronics home appliance, Proceedings of the 26th DAAAM International Symposium, pp.0877-0882, B. Katalinic (Ed.), Published by DAAAM International, ISBN 978-3-902734- 07-5, ISSN 1726-9679, Vienna, Austria.

[2] Mulc, T.; Udiljak, T. \& Ciglar, D. (2015). Structure of reconfigurable manufacturing systems, Chapter 32 in DAAAM International Scientific Book 2015, pp.369-390, B. Katalinic (Ed.), Published by DAAAM International, ISBN 978-3-902734-05-1, ISSN 1726-9687, Vienna, Austria.

[3] Jun, C.; Yoon, J.-S. \& Kim, B.H. (2017). Applications' integration and operation platform to support smart manufacturing by small and medium-sized enterprises, in: Modena, Italy.

[4] Kagermann, H.; Helbig, J.; Hellinger, A. \& Wahlster, W. (2013). Recommendations for implementing the strategic initiative INDUSTRIE 4.0: Securing the future of German manufacturing industry; final report of the Industrie 4.0 Working Group. Forschungsunion.

[5] Group, T.B.C. (2016). Winning the Industry 4.0 race; how ready are Danish manufacturers.

[6] Bejlegaard, M.; Brunoe, T.D.; Andersen, A.-L. \& Nielsen, K. (2016). Reconfigurable manufacturing potential in small and medium enterprises with low volume and high variety, 3rd International Conference on Ramp-up Management (ICRM). 
[7] Sommer, L. (2015). Industrial revolution-industry 4.0: Are German manufacturing SMEs the first victims of this revolution?, Journal of Industrial Engineering and Management, Vol. 8 (5), page numbers (1512).

[8] Kumalo, N. \& van der Poll, J.A. (2015). The role of cloud computing in addressing SME challenges in South Africa. in: Cloud Computing Research and Innovation (ICCCRI), 2015 International Conference on, pp. 139-147.

[9] Association, E.F. of the F.R. \& others (2013). Multi annual roadmap for the contractual PPP under Horizon 2020.

[10] Wang, S.; Wan, J.; Li, D. \& Zhang, C. (2016). Implementing smart factory of Industrie 4.0: an outlook, International Journal of Distributed Sensor Networks, Vol. 2016 page numbers (7).

[11] Zezulka, F.; Marcon, P.; Vesely, I. \& Sajdl, O. (2016). Industry 4.0- An introduction in the phenomenon, IFACPapersOnLine, Vol. 49 (25), page numbers (8-12).

[12] Kolberg, D. \& Zühlke, D. (2015). Lean automation enabled by industry 4.0 technologies, IFAC- PapersOnLine, Vol. 48 (3), page numbers (1870-1875).

[13] Jackson, M.; Hedelind, M.; Hellström, E.; Granlund, A. \& Friedler, N. (2011). Lean automation: requirements and solutions for efficient use of robot automation in the Swedish manufacturing industry, International Journal of Engineering Research \& Innovation, Vol. 3 (2), page numbers (36-43).

[14] Bilberg, A. \& Hadar, R. (2012). Adaptable and reconfigurable LEAN automation - a competitive solution in the Western industry, in: FAIM 2012 22nd International Conference on Flexible Automation and Intelligent Manufacturing, Helsinki.

[15] Seifermann, S.; Böllhoff, J.; Metternich, J. \& Bellaghnach, A. (2014). Evaluation of work measurement concepts for a cellular manufacturing reference line to enable low cost automation for lean machining, Procedia CIRP, Vol. 17 page numbers (588-593).

[16] Mrugalska, B. \& Wyrwicka, M.K. (2017). Towards Lean production in Industry 4.0, Procedia Engineering, Vol. 182 page numbers (466-473).

[17] Jaione, G. (2016). Three stage maturity model in SME's towards Industry 4.0, Journal of Industrial Engineering and Management, 2016 - 9(5): 1119-1128 - Online ISSN: 2013-0953 - Print ISSN: 2013-8423.

[18] Krajewski, L.J. \& Ritzman, L.P. (2005). Operations management: processes and value chains, Prentice Hall.

[19] Bicheno, J. \& Holweg, M. (2000). The Lean toolbox, PICSIE books Buckingham.

[20] Schönsleben, P.; Fontana, F. \& Duchi, A. (2017). What benefits do initiatives such as Industry 4.0 offer for production locations in high-wage countries?, Procedia CIRP, Vol. 63 page numbers (179-183).

[21] Abazi, B. (2016). An approach to the impact of transformation from the traditional use of ICT to the Internet of Things: How smart solutions can transform SMEs, IFAC-PapersOnLine, Vol. 49 (29), page numbers (148-151).

[22] Gubbi, J.; Buyya, R.; Marusic, S. \& Palaniswami, M. (2013). Internet of things (IoT): A vision, architectural elements, and future directions, Future Generation Computer Systems, Vol. 29 (7), page numbers (1645-1660).

[23] Malik, A. A.; Bilberg, A.; (2017). Framework to implement collaborative robots in manual assembly: A Lean automation approach, Proceedings of the 28th DAAAM International Symposium, B. Katalinic (Ed.), Published by DAAAM International, ISSN 1726-9679, Vienna, Austria, (in press).

[24] Grigorescu, S.; Vatau, S. \& Dobra, A. (2010). Dedicated robot-robot cooperation, Chapter 55 in DAAAM International Scientific Book 2010, pp. 633-644, B. Katalinic (Ed.), Published by DAAAM International, ISBN 9783-901509-74-2, ISSN 1726-9687, Vienna, Austria.

[25] Zuehlke, D. (2010). SmartFactory-Towards a factory-of-things, Annual Reviews in Control, Vol. 34 (1), page numbers $(129-138)$

[26] Radziwon, A.; Bilberg, A.; Bogers, M. \& Madsen, E.S. (2014). The Smart Factory: Exploring adaptive and flexible manufacturing solutions, Procedia Engineering, Vol. 69 page numbers (1184-1190).

[27] Zuehlke, D. (2008). Smartfactory-from vision to reality in factory technologies. in: Proceedings of the 17th IFAC World Congress, pp. 82-89.

[28] Wagner, U.; AlGeddawy, T.; ElMaraghy, H. \& Myller, E. (2012). The state-of-the-art and prospects of learning factories. Procedia CIRP, $\quad$ Vol. 3 page numbers 